OPEN ACCESS

Edited by:

Brad Haverkos,

University of Colorado Hospital,

United States

Reviewed by:

Narendranath Epperla,

The Ohio State University,

United States

Yago Nieto,

University of Texas MD Anderson

Cancer Center, United States

*Correspondence:

Ann S. LaCasce

ann_lacasce@dfci.harvard.edu

Specialty section:

This article was submitted to

Hematologic Malignancies,

a section of the journal

Frontiers in Oncology

Received: 16 November 2018

Accepted: 05 February 2019

Published: 07 March 2019

Citation:

Crombie JL and LaCasce AS (2019) Epstein Barr Virus Associated B-Cell Lymphomas and latrogenic Lymphoproliferative Disorders.

Front. Oncol. 9:109.

doi: 10.3389/fonc.2019.00109

\section{Epstein Barr Virus Associated B-Cell Lymphomas and latrogenic Lymphoproliferative Disorders}

\author{
Jennifer L. Crombie and Ann S. LaCasce* \\ Department of Medical Oncology, Dana-Farber Cancer Institute, Boston, MA, United States
}

Epstein-Barr virus (EBV) is a ubiquitous herpesvirus, affecting up to $90 \%$ of the population. EBV was first identified as an oncogenic virus in a Burkitt lymphoma cell line, though subsequently has been found to drive a variety of malignancies, including diffuse large B-cell lymphoma (DLBCL) and other lymphoma subtypes. EBV has a tropism for B-lymphocytes and has the unique ability to exist in a latent state, evading the host immune response. In cases of impaired cell mediated immunity, as in patients with advanced age or iatrogenic immune suppression, the virus is able to proliferate in an unregulated fashion, expressing viral antigens that predispose to transformation. EBV-positive DLBCL not otherwise specified, which has been included as a revised provisional entity in the 2016 WHO classification of lymphoid malignancies, is thought to commonly occur in older patients with immunosenescence. Similarly, it is well-established that iatrogenic immune suppression, occurring in both transplant and non-transplant settings, can predispose to EBV-driven lymphoproliferative disorders. EBV-positive lymphoproliferative disorders are heterogeneous, with variable clinical features and prognoses depending on the context in which they arise. While DLBCL is the most common subtype, other histologic variants, including Burkitt lymphoma, NK/T-cell lymphoma, and Hodgkin lymphoma can occur. Research aimed at understanding the underlying biology and disease prevention strategies in EBV-associated lymphoproliferative diseases are ongoing. Additionally, personalized treatment approaches, such as immunotherapy and adoptive T-cell therapies, have yielded encouraging results, though randomized trials are needed to further define optimal management.

Keywords: PTLD, post-transplant lymphomatous disorder, ebv, Epstein-Barr virus, lymphoma, DLBCL, Burkitt leukemia/lymphoma (BL)

\section{INTRODUCTION}

EBV is a ubiquitous human herpesvirus, affecting up to $90 \%$ of the population depending on the region (1). EBV was the first oncogenic virus identified, initially identified in association with a Burkitt lymphoma (BL) cell line, though subsequently associated with a variety of malignancies, including a variety of lymphoma subtypes (2).

EBV initially infects epithelial cells of the oropharynx, prior to replication and spread to B-lymphocytes. A key feature that provides oncogenic potential is the capacity of the virus to exist in a latent state within B-cells $(3,4)$. One theory of EBV pathogenesis involves the transit of infected 
B-cells through the germinal center, where they develop into resting memory $\mathrm{B}$-cells, thus allowing the virus to remain quiescent and occasionally reactivating to infect new B-cells (5). Latent EBV subsequently predisposes to malignant transformation, especially in the setting of impaired cell mediated immunity and chronic antigenic activation, where the virus replicates and expresses viral antigens that promote growth and survival of the cell.

Depending on the viral gene expression pattern, EBV establishes one of three latency patterns.

Latency type I, in which Epstein-Barr nuclear antigen I (EBNA-1) and two small non-coding Epstein-Barr- encoded RNAs (EBERs) are expressed, is generally thought to be associated with $\mathrm{BL}$ (3). In latency type II, the virus expresses EBNA-1, EBERs and the latent membrane proteins (LMPs), LMP-1, LMP-2A, and LMP-2B (3). This latency pattern has been associated with Hodgkin lymphoma (HL) and T-cell non-Hodgkin lymphomas. Lastly, latency type III results in expression of the entire EBV repertoire, including EBNAs, EBERs, and LMPs, and is seen in association with posttransplant lymphoproliferative disorders (PTLDs) and other immunocompromised states $(3,6)$. EBV-positive $(\mathrm{EBV}+)$ diffuse large B-cell lymphoma (DLBCL) is associated with both latency type II and III patterns (7). EBV latency proteins play a critical role in disrupting key signaling pathways that promote lymphomagenesis. LMP-1, for example, can behave as an oncogene leading to constitutive signaling, B-cell activation, and upregulation of anti-apoptotic proteins (8). EBNAs can similarly serve as transcription factors, promoting the growth and transformation of B-cells (8).

EBV has been associated with the pathogenesis of a variety of malignancies, most notably B-cell and T-cell lymphomas. In this review, we will discuss the B-cell lymphoproliferative disorders associated with EBV, which often occur in the setting of immune suppression. We will highlight the defining clinical characteristics of these lymphoma subtypes, predisposing and prognostic factors, and general treatment algorithms. Importantly, we will highlight recent advances in treatment approaches, including the application of immune-based and cellular therapies, that have potential to be paradigm shifting in the management of EBV-associated disease independent of histologic subtype.

\section{BURKITT LYMPHOMA}

EBV was first identified in association with a BL cell line (2). $\mathrm{BL}$ is an aggressive B-cell non-Hodgkin lymphoma (NHL), that can be classified into three distinct variants. Endemic BL primarily affects children in equatorial Africa and is nearly universally associated with EBV infection. Alternatively, sporadic $\mathrm{BL}$, which occurs worldwide, is a rarer subtype of NHL that is rarely associated with the virus. The third variant, immunodeficiency-related BL commonly occurs in the context of human immunodeficiency virus (HIV) infection. The role of EBV in this subtype is less clear than in endemic BL, though is seen in up to $40 \%$ of cases (9).

Across subtypes, BL is characterized pathologically by monomorphic medium-sized cells with a proliferation index of nearly $100 \%$. There is also a resulting "starry sky" appearance due the presence of numerous tangible body macrophages, phagocytosing abundant apoptotic debris (10). BL typically expresses pan-B-cell antigens, including CD19, CD20, and CD79b and co-expresses CD10 and BCL-6. A defining feature is the presence of translocation between the $c-M Y C$ oncogene and the immunoglobulin heavy chain $(I g H)$ or in rarer cases, the immunoglobulin light chain gene. MYC subsequently serves as a master regulator of oncogenesis, promoting proliferation, apoptosis, differentiation, and metabolism (11).

Endemic BL accounts for approximately half of pediatric malignancies and up to $90 \%$ of lymphoma diagnoses in equatorial Africa (9). These lymphomas primarily present as isolated masses of the jaw and occur with a male predominance. Interestingly, endemic $\mathrm{BL}$ is restricted to geographic regions in which Plasmodium falciparum malaria is holoendemic, suggesting that $\mathrm{EBV}$ and malaria infections cooperate in the predisposition of BL. It has been proposed that malaria has immunostimulatory effects on B-cells and results in impairment of T-cell immunity, allowing for selective activation of EBV-infected memory B-cells. One proposed mechanism is the binding of $P$. falciparum to toll-like receptor- 9 , which can induce enzyme activation-induced cytidine deaminase, thus predisposing to genomic instability $(9,12)$

While sporadic BL is highly treatable with intensive chemotherapy, access to high-intensity therapy is often limited for patients with endemic disease (13-23) (Table 1). A variety of chemotherapy regimens, including those which are low and high intensity, are used throughout sub-Saharan Africa. Outcomes for these patients are unfortunately much worse than in resourcerich countries, with overall survival ranging from 51 to $67 \%$ (24).

\section{EBV-POSITIVE DIFFUSE LARGE B-CELL LYMPHOMA, NOS}

In addition to its association with $\mathrm{BL}, \mathrm{EBV}$ has been linked to other lymphoma subtypes, including DLBCL. In 2003, EBV+ DLBCL was first described as a distinct entity among elderly patients with in situ hybridization demonstrating an association with EBV (25). LMP1 was also detected in all cases described (25). EBV-associated DLBCL of the elderly was subsequently included as a provisional entity in the 2008 World Health Organization (WHO) classification of lymphoid malignancies, defined as a monoclonal large B-cell proliferation occurring in patients over the age of 50 and without known immunodeficiency or history of lymphoma. This disease was thought to occur in setting of immunosenescence, given shared features with post-transplant lymphoproliferative disorder (PTLD) (26). More recently, this entity has been appreciated in younger, immunocompetent hosts, without an association with poor outcome $(27,28)$. This information has led to the revised entity, EBV+ DLBCL not otherwise specified (NOS) in the 2016 WHO criteria (29).

Pathologically, EBV+ DLBCL generally demonstrates a diffuse and polymorphic proliferation of large lymphoid cells with a varying degree of reactive components such as small lymphocytes, plasma cells, histiocytes, and epithelioid cells (30). Two morphologic variants, monomorphic and polymorphic, have been recognized, though the prognostic significance of these subtypes is not clear. Malignant cells express CD19, 


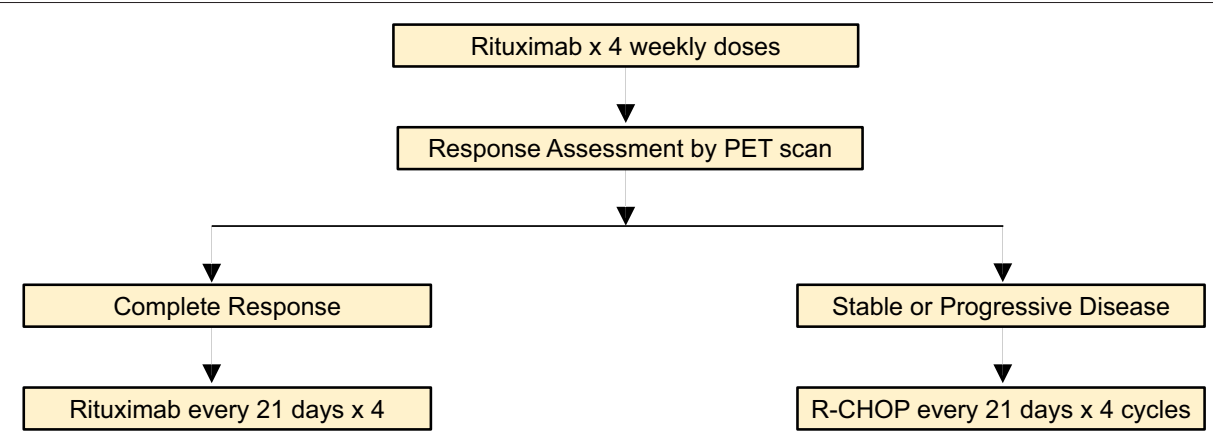

FIGURE 1 | Risk-adaptive treatment approach for DLBCL PTLD (31).

TABLE 1 | Treatment options for patients with Burkitt Lymphoma.

\begin{tabular}{lll}
\hline Treatment & EFS/PFS/CCR & OS \\
\hline CODOX-M/IVAC & 2-year EFS: 92\% (15) & 2-year OS: 73\% (16) \\
& 2-year EFS: 65\% (16) & 2-year OS: 67\% (17) \\
& 2-year PFS: 64\% (17) & \\
GALGB Regimen & 3-year EFS: 52\% (cohort 1), & 3-year OS: 54\% (cohort 1), \\
& 45\% (cohort 2) (18) & 50\% (cohort 2) (18) \\
& 3-year EFS: 74\% (19) & 2-year OS: 78\% (19) \\
HyperCVAD +/-R & 3-year CCR: 61\% (20) & 3-year OS: 49\% (20) \\
& 3-year EFS: 80\% (21) & 3-year OS: 89\% (21) \\
Dose-adjusted & EFS: 95\% (14) & OS: 100\% (14) \\
R-EPOCH & & \\
\hline
\end{tabular}

CODOX-M/IVAC, cyclophosphamide, vincristine, doxorubicin, methotrexate, ifosfamide, etoposide, cytarabine.

CALGB, Cancer and Leukemia Group B.

$C V A D$, cyclophosphamide, vincristine, doxorubicin, dexamethasone, rituximab.

$R$-EPOCH, rituximab, etoposide, prednisone, vincristine, cyclophosphamide, doxorubicin; EFS/PFS/CCR, event-free survival/progression-free survival/continuous complete response; OS, overall survival.

CD20, CD22, and CD79. CD30 is expressed in 40\% of cases. Most cases are of activated $\mathrm{B}$-cell (ABC) subtype, expressing MUM1/IRF4 and staining negative for CD10 and BCL-6. EBV latent membrane protein 1 (LMP1) is expressed in approximately two-thirds of cases, which is suggestive of EBV latency type II (32) (Table 2). EBV nuclear antigen 2 (EBNA2), which denotes EBV latency type III, typically comprises the remaining one-third (32).

As the original name suggests, EBV + DLBCL is more common in elderly patients, and occurs with a male predominance. It is thought to be associated with poor outcomes as compared to EBV-negative (EBV-) counterparts, though data is conflicting. A Japanese study demonstrated that EBV positivity was associated with an age $>60$ years, advanced stage, more than one extranodal site of involvement, higher International Prognostic Index (IPI) risk score, presence of B-symptoms, and poorer outcome in response to initial treatment, as compared to EBV- controls (33). This translated to a significantly poorer overall survival of 35.8 months in the EBV+ group vs. an overall survival that was not reached in the EBV- group (33). It should be noted that patients in this study were treated with CHOP (cyclophosphamide, doxorubicin, vincristine, and prednisone)
TABLE 2 | Epstein-Barr virus latency patterns.

\begin{tabular}{lll}
\hline $\begin{array}{l}\text { Latency } \\
\text { pattern }\end{array}$ & EBV gene expression pattern & $\begin{array}{l}\text { EBV-associated } \\
\text { lymphoma }\end{array}$ \\
\hline Type I & EBNA-1 & Burkitt Lymphoma \\
& EBERs & Hodgkin lymphoma \\
Type II & EBNA-1 & T-cell NHL \\
& EBER & EBV+ DLBCL \\
& LMPs: LMP-1, LMP-2A, and LMP-2B & PTLD \\
Type III & Entire EBV repertoire: including & EBV+ DLBCL \\
& EBNAs, EBERs, and LMPs & \\
\hline
\end{tabular}

EBV, Epstein-Barr Virus; EBNA, Epstein-Barr nuclear antigen; EBER, Epstein-Barrencoded RNA; LMP, latent membrane proteins.

chemotherapy and had an EBV-encoded RNA (EBER) cutoff of $20 \%$ (33). Another study demonstrated that age $>70$ years and the presence of B-symptoms were independent predictors of survival in this disease, thus defining a distinct prognostic model to define three risk groups (30). In Western countries, in which rituximab was added to a CHOP chemotherapy backbone (R-CHOP) and EBV positivity was defined by EBER $>10 \%$ of cellular staining, there were no appreciable differences between the clinical characteristics of EBV + and EBV- disease, however, CD30 positivity in conjunction with EBV positivity, was found to confer an inferior prognosis (32). As a cutoff for EBV positivity has not been defined and treatment has not been uniform, the impact of EBV positivity on outcome remains to be determined. Differences may also be attributable to variation in EBV stains or host factors across geographic regions.

Despite conflicting reports on clinical and prognostic features, EBV + DLBCL does have a unique molecular phenotype as compared to EBV-negative disease. Specifically, gene expression profiling demonstrates that EBV+ DLBCL has a molecularly distinct profile (7). Specifically, gene expression profiling of $\mathrm{EBV}+\mathrm{DLBCL}$ demonstrated upregulation of genes involved in NF- $\mathrm{B}$ activity, cell proliferation, cell-cycle progression, and cell metabolism. Immunohistochemistry has also identified increased expression of p50 and pSTAT3, components of NF- $\kappa$ B signaling, in EBV+ DLBCL (32). While these differences have been appreciated, the prognostic and 
TABLE 3 | WHO classification of post-transplant lymphoproliferative disorders.

\begin{tabular}{|c|c|c|}
\hline PTLD category & Type & EBV status \\
\hline $\begin{array}{l}\text { Early lesions } \\
\text { (Non-destructive) }\end{array}$ & $\begin{array}{l}\text { Plasmacytic hyperplasia } \\
\text { Infectious mononucleosis-like PTLD } \\
\text { Florid hyperplasia }\end{array}$ & Almost 100\% \\
\hline $\begin{array}{l}\text { Polymorphic } \\
\text { (Destructive) }\end{array}$ & $\begin{array}{l}\text { Polyclonal and Monoclonal } \\
\text { proliferations }\end{array}$ & $>90 \%$ \\
\hline $\begin{array}{l}\text { Monomorphic } \\
\text { (Destructive) }\end{array}$ & $\begin{array}{l}\text { Monoclonal Non-Hodgkin } \\
\text { Lymphomas, including: } \\
\text { - Diffuse large B-Cell lymphoma } \\
\text { ( } 60 \%) \\
\text { - Burkitt lymphoma } \\
\text { - Plasma cell myeloma } \\
\text { - T-cell lymphoma }\end{array}$ & $\begin{array}{l}\text { Both EBV }+ \text { and EBV- } \\
\text { (EBV- in } 10-48 \% \text { of } \\
\text { cases) }\end{array}$ \\
\hline $\begin{array}{l}\text { Hodgkin } \\
\text { lymphoma } \\
\text { (Destructive) }\end{array}$ & Monoclonal & $>90 \%$ \\
\hline
\end{tabular}

therapeutic implications of these distinct molecular features remain unclear.

The standard of care for frontline therapy remains treatment with chemoimmunotherapy, traditionally R-CHOP, with variable responses reported worldwide. Emerging treatment strategies, including viral directed approaches and use of immune-based therapies are an active area of investigation and are discussed in further detail below. While these therapies have primarily been studied in the context of post-transplant lymphoproliferative disorder (PTLD), they have broad implications across EBVdriven lymphomas such as EBV+ DLBCL NOS.

\section{IATROGENIC LYMPHOPROLIFERATIVE DISORDERS ASSOCIATED WITH EBV: TRANSPLANT AND NON-TRANSPLANT SETTINGS}

\section{Post-transplant Lymphoproliferative Disorder}

PTLD is a serious complication of solid organ and allogenic stem cell transplantation. With the exception of skin cancer and in situ cervical cancer, PTLD is the most common malignancy seen after solid organ transplantation (34). The risk of PLTD is dependent on a variety of factors, including the type transplant, the immunosuppression used, and EBV seronegativity of the recipient prior to transplant. Following solid organ transplant, PTLD is thought to be derived from recipient lymphoid cells, while PTLD following hematopoietic stem cell transplantation are almost exclusively of donor origin $(35,36)$. Over the past $10-$ 15 years, there has been an increase in the incidence of PTLD, presumably due to an increased number of organ transplants performed, use of novel immunosuppressive therapies, and an increased awareness of the disease $(37,38)$.

The WHO classifies PTLD into six categories, with three types of non-destructive PTLDs, including plasmacytic hyperplasia, infectious mononucleosis-like PTLD, and florid hyperplasia, as well as polymorphic lesions, monomorphic lesions, and classical HL $(29,38,39)$ (Table 3). The majority of PTLDs are of
TABLE 4 | Risk factors for PTLD (38).

\begin{tabular}{|c|c|}
\hline Solid organ transplant & $\begin{array}{l}\text { Allogeneic stem cell } \\
\text { transplantation }\end{array}$ \\
\hline Type of transplant & Degree of HLA mismatch \\
\hline $\begin{array}{l}\text { - Multi-organ and intestinal transplants: } \\
\text { > } 20 \% \\
\text { - Lung transplants: } 3-10 \% \\
\text { - Heart transplants: } 2-8 \% \\
\text { - Liver transplants: } 1-5.5 \% \\
\text { - Pancreatic transplants: } 0.5-5 \% \\
\text { - Kidney transplants: } 0.8-2.5 \%\end{array}$ & $\begin{array}{l}\text { - Haploidentical transplants: } \leq 20 \% \\
\text { - Unrelated donor: 4-10\% } \\
\text { - Umbilical cord transplant: } 4-5 \% \\
\text { - HLA-identical related: } 1-3 \%\end{array}$ \\
\hline Immunosuppressive therapy & Type of GVHD prophylaxis \\
\hline $\begin{array}{l}\text { - Higher intensity and prolonged duration } \\
\text { of therapy associated with higher risk } \\
\text { - Use of Anti-thymocyte globulin (ATG), } \\
\text { Calcineurin inhibitors, Anti-CD3 (OKT3), } \\
\text { Tacrolimus, Cyclosporine }\end{array}$ & $\begin{array}{l}\text { - T-cell depletion associated with } \\
\text { highest risk }\end{array}$ \\
\hline $\begin{array}{l}\text { EBV mismatch between recipient and } \\
\text { donor }\end{array}$ & $\begin{array}{l}\text { EBV mismatch between recipient } \\
\text { and donor }\end{array}$ \\
\hline - Relative risk between 10 and 75 & \\
\hline
\end{tabular}

B-cell origin and driven by EBV, though EBV- cases have been reported in 10-48\% of cases (40). As T-cell responses are impaired in the post-transplant setting, EBV is able to promote B-cell proliferation and potentially transformation in an unregulated fashion. These lymphomas, like other lymphomas arising in the setting of immunosuppression, typically express a latency type III program. The pathogenesis of EBV- PTLD is less clearly understood. PTLD is most commonly seen within the 1st year following transplantation, though a subset of PTLD, especially those that are EBV- can occur late. As gene expression profiling reveals biologically distinct categorization among EBV + and EBV- disease, it has been raised whether EBVPTLD represents lymphoma that coincidentally occurs in the setting of transplantation, though additional analyses dissecting biologic and clinical differences between these entities are required $(40,41)$. The most common subtype of monomorphic PTLD is DLBCL, comprising $~ 60 \%$ of cases in one study, though other histologies including BL, plasma cell neoplasms and T-cell lymphomas have been seen $(34,42)$. Classical HL-type PTLD is very rare, though can occur, especially late after transplant (43).

\section{Risk Factors}

With both solid organ and hematologic stem cell transplants, the risk of PTLD is dependent on the type of transplant performed. In adults, the risk is highest following multi-organ and intestinal transplants $(>20 \%)$, followed by lung transplants (3-10\%), heart transplants $(2-8 \%)$, liver transplants $(1-5.5 \%)$, pancreatic transplants $(0.5-5 \%)$, and kidney transplants $(0.8-$ $2.5 \%)(34,38,42,44)$ (Table 4). In addition to variation in histocompatibility among organ types and requirements for immunosuppression, transplanted organs can have varying degrees of $\mathrm{EBV}+$ lymphoid tissue within the graft, which contribute to the variation in risk (45). In the case of allogeneic stem cell transplant, the risk of PTLD risks appears to be associated with the degree of HLA mismatch, with 
highest rates of PTLD occurring after unrelated or HLAmismatched grafts $(46,47)$. With the advent of haploidentical transplantation, the incidence of PTLD has further increased, though this risk may be abrogated with the use of post-transplant cyclophosphamide for prophylaxis against graft vs. host disease (GVHD) (48).

The degree, duration and type of immunosuppression are also major factors that impact the risk of PTLD. Several studies have demonstrated rising rates of PTLD in the setting of more potent immunosuppression (42, 44, 49). Although it can difficult to identify the specific contribution of one drug within a combination immunosuppressive regimen, antithymocyte globulin (ATG), calcineurin inhibitors, anti-CD3 (OKT3), tacrolimus, and cyclosporine have all been specifically implicated in PTLD predisposition, the risks can vary across studies (49). In one study of 200,000 kidney recipients, immunosuppression with cyclosporine did not confer added risk compared with azathioprine/steroid treatment, whereas treatment with tacrolimus increased the risk $\sim 2$-fold (44). In this study, OKT3 or ATG were also been found to significantly increase lymphoma rates. Patients treated with tacrolimus also been found to have an increased risk of PTLD as compared to those treated with cyclosporine and antimetabolites, mycophenolate and azathioprine, in other studies (50). Following allogeneic transplant, the type of GVHD prophylaxis also appears to contribute to PTLD risk, with T-cell depletion being associated with highest incidence of lymphoma (46).

EBV mismatch between recipient and donor is the strongest prognostic factor for the development of PTLD. In one study, EBV mismatch among renal transplant donor and recipients (donor positive/recipient negative) was associated with a 35$42 \%$ increase in the incidence of PTLD (51). A similar study among solid organ transplant recipients demonstrated a 24fold increased risk of PTLD among EBV seropositive patients (52). Interestingly, CMV seronegativity further amplifies risk, suggesting that $\mathrm{CMV}$ viremia may further predispose to EBV viremia. Increased EBV naivety in children as compared to adults is also thought to contribute to the increased risk of PTLD in the pediatric population, where primary EBV infections have the potential to drive lymphomagenesis (38).

\section{Prognosis}

PTLD has traditionally been associated with poor outcomes, though survival rates have improved with the incorporation of early rituximab-based therapy (53). While disease presentations can be heterogeneous, patients are frequently diagnosed with advanced stage disease with extranodal involvement, including high rates of graft and gastrointestinal disease. In one study, $72 \%$ of patients were diagnosed with Ann Arbor stage III/IV disease and $78 \%$ of patients displayed one or more extranodal sites of disease (42). In addition to the IPI, the presence of CNS and bone marrow involvement, as well as hypoalbuminemia, have been shown to have prognostic value (53). A multivariable model for survival constructed using three factors: poor performance status, monomorphic disease, and graft organ involvement, has also had superior performance to the IPI in separating survival outcomes of patients, though additional prospective studies are required to validate the use of this tool (54). A French study, which included 500 renal transplant recipients with PTLD, similarly demonstrated that advanced age, elevated creatinine, elevated lactate dehydrogenase, disseminated lymphoma, brain localization, invasion of serous membranes, monomorphic PTLD, and T-cell PTLD were independent prognostic indicators of poor response (55). While the resulting prognostic score effectively stratifies risk, it remains unclear whether it provides additional prognostication outside of traditional models such as the IPI (56). More recently, risk adaptive therapy has been utilized for the management of PTLD, with response to single agent rituximab induction serving as a prognostic factor for overall survival (31).

\section{Treatment}

Reduction in immunosuppression is the mainstay of initial therapy for patients with PTLD. While this treatment approach must always be weighed with the risk of graft rejection, studies have demonstrated that reduction of immune suppression alone can result in partial PTLD regression in a large subset of patients with both polymorphic and monomorphic disease (57). This typically involves reduction in calcineurin inhibitors by at least $50 \%$ and discontinuation of azathioprine or mycophenolate mofetil (58). Following allogenic transplant, reduction in immunosuppression is defined as a sustained decrease of at least $20 \%$ of the daily dose of immunosuppressive drugs with the exception of low-dose corticosteroid therapy (59). Early disease stage predicts favorable responses to reduction in immunosuppression, while older age, bulky disease and advanced stage are associated with poor responses with this strategy (57). While responses have been reported in monomorphic disease, patients invariably require addition therapy for adequate disease control.

In addition to tapering of immune suppression, rituximab with or without chemotherapy is an effective therapeutic option in PTLD. The phase II PTLD-1 trial initially investigated the efficacy of 4 weekly doses of rituximab followed by four cycles of CHOP chemotherapy in adult solid organ transplant recipients with CD20+ PTLD (60). Interestingly, this study demonstrated that $60 \%$ of patients had a complete or partial response to rituximab monotherapy prior to the initiation of chemotherapy. The high responses to single agent rituximab prompted a follow up phase II study to assess whether rituximab consolidation was an adequate treatment approach for patients with PTLD who achieved a complete response to rituximab induction (31). In patients who did not achieve a complete response, treatment proceeded with four additional cycles of rituximab plus $\mathrm{CHOP}$, as in the PTLD-1 trial. This treatment approach resulted in an overall response rate of $88 \%$ and median overall survival of 6.6 years, which were similar to outcomes of patients receiving chemotherapy (Figure 1). While risk stratified sequential therapy is an appropriate strategy for DLBCL PTLD, disease specific treatment approaches are utilized for other histologic subtypes.

The expression of viral antigens makes EBV + PTLD an attractive candidate for immune based therapies. EBV-specific cytotoxic lymphocytes have been successfully utilized following allogeneic stem cell transplant, where EBV+ PTLD is known 
to originate from donor lymphocytes, thus reconstituting T-cell immunity against the virus. One study demonstrated that infusion of EBV-specific cytotoxic T-lymphocytes (CTLs) generated from the transplant donor both prevented and treated PTLD in the post allogeneic stem cell setting (61). In this study none of 110 patients who used CTLs for prophylaxis developed PTLD and 11 of 13 patients with PTLD achieved a complete remission (61). Similarly, autologous CTLs have been successfully utilized for prevention of PTLD in solid organ transplant recipients, in which PTLD is primarily thought to be derived from recipient lymphocytes, though the length of persistence and antiviral activity of the CTLs does not appear as robust as in allogenic stem cell transplant recipients (62). Partially HLAmatched CTLs have subsequently been identified as an option for solid organ transplant recipients, resulting in an overall response rate of $64 \%$ at 5 weeks, though are associated with prolonged production times (63). Autologous $\mathrm{T}$ cells directed to the LMP2 or LMP1 and LMP2 antigens have further demonstrated promising results in patients with a range of EBV+ lymphomas (64). Additional prospective studies will be required to establish the feasibility and efficacy of these approaches in a larger patient cohorts.

Data has suggested that EBV-associated malignancies, such as PTLD and classical HL, share certain mechanisms of immune evasion $(65,66)$. Therefore, there has been interest in utilizing immune checkpoint inhibitors in PTLD, given known efficacy in cHL (67). Programmed cell death ligand 1 (PD-L1) is expressed on antigen-presenting cells that bind the PD-1 receptor on $\mathrm{T}$ cells, thus inhibiting $\mathrm{T}$-cell receptor signaling. Recent data suggests that EBV plays a role in increasing PD-L1 in PTLD, further supporting the role of checkpoint inhibition in this disease (66). PDL-1, PDL-2, and PD-1 were also found to be positive in $67 \%$ of PTLD cases following solid organ transplantation in one study (68). While checkpoint inhibitors have been utilized in the setting of both solid organ and allogeneic stem cell transplant, additional studies will be required to determine the safety, efficacy and risk of graft rejection or graft vs. host disease with this approach.

\section{Prevention}

The role of antiviral medications for the prevention of PTLD has remained controversial. A recent meta-analysis found no significant difference in the rate of EBV+ PTLD in solid organ transplant recipients among those who received prophylaxis, including acyclovir, valacyclovir, ganciclovir, valganciclovir, compared with those who did not receive prophylaxis (69). While these therapies are moderately effective in suppressing viral replication and shedding during acute or lytic replication, they are not effective against EBV given the latent state of replication (70). Vaccines against EBV, specifically those targeting pg350, have thus far been unsuccessful, though the identification of alternative epitopes for vaccine generation are underway (71). Pre-emptive therapy with rituximab in patients with positive EBV DNA following allogenic stem cell transplantation has also been associated with reduction in PTLD incidence and abrogation of PTLD-related mortality $(72,73)$. Pre-emptive strategies including tapering of immune suppression and rituximab therapy are also used following solid organ transplant, though practices appear less uniform (74).

\section{latrogenic Immunodeficiency-Associated Lymphoproliferative Disorder-Non-transplant Related}

Lymphoproliferative disorders are known to occur frequently in the context of impaired immunity. As such, patients outside of the transplant setting, including those using immunomodulatory agents, are at increased risk for lymphoproliferative disorders, especially EBV-driven disease. The WHO defines a subset of "other iatrogenic immunodeficiency associated lymphoproliferative disorders," composed primarily of lymphomas occurring in patients receiving immunosuppressive therapy for autoimmune disease. In particular, EBV+ lymphoproliferative disorders have been seen in patients on methotrexate, tumor necrosis factor $(\mathrm{TNF}) \alpha$ inhibitors, fludarabine and mycofenolate mofetil (75-78). The presence of an underlying autoimmune disease may also play a role in disease pathogenesis, though the association remains less clear. One study of rheumatoid arthritis associated lymphoproliferative disorders, demonstrated a range of lymphoid histologies, including DLBCL, classical HL, polymorphic B-cell lymphoproliferative disorder, follicular lymphoma, composite lymphoma, reactive lymphadenitis, and peripheral T-cell lymphoma (75). Of note, EBV was positive in $60 \%$ of patients and withdrawal of methotrexate resulted in disease regression in 59\% of cases, suggesting similar characteristics to PTLD (75). While treatment algorithms are less clearly defined in these lymphoproliferative disorders as compared to PTLD, treatment typically consists of standard of care therapies for the specific histology seen.

\section{CONCLUSIONS}

EBV is a common herpesvirus that has a unique ability to evade the host immune response and exist in a latent form within B-lymphocytes. Impairments in cellular immunity, occurring in the setting of concurrent infections, older age, solid organ, and hematopoietic stem cell transplantation, and immunosuppressive therapies, results in a particularly high risk of EBV reactivation and B-cell transformation. EBVassociated lymphoproliferative disorders have heterogeneous presentations with variable responses to therapy. However, given a shared underlying biology and overlapping clinical features, adaptations to the current classification structure of immunodeficiency-associated lymphoproliferative disorders have been proposed (79). Ongoing research aimed at novel treatment approaches, especially those utilizing immune-based therapies have demonstrated promising results in PTLD, and have implications across EBV-driven histologies. Ongoing research aimed at understanding the biology of EBV as well as disease prevention and treatment strategies will be fundamental in improving outcomes for patients with EBVassociated lymphoproliferative diseases. 


\section{DATA AVAILABILITY}

All datasets generated for this study are included in the manuscript and/or the supplementary files.

\section{REFERENCES}

1. Ok CY, Li L, Young KH. EBV-driven B-cell lymphoproliferative disorders: from biology, classification and differential diagnosis to clinical management. Exp Mol Med. (2015) 47:e132. doi: 10.1038/emm.2014.82

2. Epstein MA, Achong BG, Barr YM. Virus particles in cultured lymphoblasts from Burkitt's lymphoma. Lancet. (1964) 1:702-3. doi: 10.1016/S0140-6736(64)91524-7

3. Carbone A, Gloghini A, Dotti G. EBV-associated lymphoproliferative disorders: classification and treatment. Oncologist. (2008) 13:577-85. doi: 10.1634/theoncologist.2008-0036

4. Kang MS, Kieff E. Epstein-Barr virus latent genes. Exp Mol Med. (2015) 47:e131. doi: 10.1038/emm.2014.84

5. Thorley-Lawson DA, Hawkins JB, Tracy SI, Shapiro M. The pathogenesis of Epstein-Barr virus persistent infection. Curr Opin Virol. (2013) 3:227-32. doi: 10.1016/j.coviro.2013.04.005

6. Healy JA, Dave SS. The role of EBV in the pathogenesis of diffuse large B cell lymphoma. Curr Top Microbiol Immunol. (2015) 390(Pt. 1):315-37. doi: 10.1007/978-3-319-22822-8_13

7. Castillo JJ, Beltran BE, Miranda RN, Young KH, Chavez JC, Sotomayor EM. EBV-positive diffuse large B-cell lymphoma of the elderly: 2016 update on diagnosis, risk-stratification, and management. Am J Hematol. (2016) 91:529-37. doi: 10.1002/ajh.24370

8. Cohen JI, Bollard CM, Khanna R, Pittaluga S. Current understanding of the role of Epstein-Barr virus in lymphomagenesis and therapeutic approaches to EBV-associated lymphomas. Leuk Lymphoma. (2008) 49(Suppl. 1):27-34. doi: 10.1080/10428190802311417

9. Molyneux EM, Rochford R, Griffin B, Newton R, Jackson G, Menon G, et al. Burkitt's lymphoma. Lancet. (2012) 379:1234-44. doi: 10.1016/S0140-6736(11)61177-X

10. Ferry JA. Burkitt's lymphoma: clinicopathologic features and differential diagnosis. Oncologist. (2006) 11:375-83. doi: 10.1634/theoncologist.11-4-375

11. Chen H, Liu H, Qing G. Targeting oncogenic Myc as a strategy for cancer treatment. Signal Transduct Target Ther. (2018) 3:5. doi: 10.1038/s41392-018-0008-7

12. Parroche P, Lauw FN, Goutagny N, Latz E, Monks BG, Visintin A, et al. Malaria hemozoin is immunologically inert but radically enhances innate responses by presenting malaria DNA to Toll-like receptor 9. Proc Natl Acad Sci USA. (2007) 104:1919-24. doi: 10.1073/pnas.0608745104

13. Lacasce A, Howard O, Lib S, Fisher D, Weng A, Neuberg D, et al. Modified magrath regimens for adults with Burkitt and Burkitt-like lymphomas: preserved efficacy with decreased toxicity. Leuk Lymphoma. (2004) 45:761-7. doi: 10.1080/1042819031000141301

14. Barnes JA, Lacasce AS, Feng Y, Toomey CE, Neuberg D, Michaelson JS, et al. Evaluation of the addition of rituximab to CODOX-M/IVAC for Burkitt's lymphoma: a retrospective analysis. Ann Oncol. (2011) 22:1859-64. doi: 10.1093/annonc/mdq677

15. Dunleavy K, Pittaluga S, Shovlin M, Steinberg SM, Cole D, Grant C, et al. Lowintensity therapy in adults with Burkitt's lymphoma. N Engl J Med. (2013) 369:1915-25. doi: 10.1056/NEJMoa1308392

16. Magrath I, Adde M, Shad A, Venzon D, Seibel N, Gootenberg J, et al. Adults and children with small non-cleaved-cell lymphoma have a similar excellent outcome when treated with the same chemotherapy regimen. J Clin Oncol. (1996) 14:925-34. doi: 10.1200/JCO.1996.14.3.925

17. Mead GM, Sydes MR, Walewski J, Grigg A, Hatton CS, Pescosta $\mathrm{N}$, et al. An international evaluation of CODOX-M and CODOX$\mathrm{M}$ alternating with IVAC in adult Burkitt's lymphoma: results of United Kingdom Lymphoma Group LY06 study. Ann Oncol. (2002) 13:1264-74. doi: 10.1093/annonc/mdf253

18. Mead GM, Barrans SL, Qian W, Walewski J, Radford JA, Wolf M, et al. A prospective clinicopathologic study of dose-modified CODOX-M/IVAC

\section{AUTHOR CONTRIBUTIONS}

All authors listed have made a substantial, direct and intellectual contribution to the work, and approved it for publication.

in patients with sporadic Burkitt lymphoma defined using cytogenetic and immunophenotypic criteria (MRC/NCRI LY10 trial). Blood. (2008) 112:224860. doi: 10.1182/blood-2008-03-145128

19. Rizzieri DA, Johnson JL, Niedzwiecki D, Lee EJ, Vardiman JW, Powell BL, et al. Intensive chemotherapy with and without cranial radiation for Burkitt leukemia and lymphoma: final results of Cancer and Leukemia Group B Study 9251. Cancer. (2004) 100:1438-48. doi: 10.1002/cncr.20143

20. Rizzieri DA, Johnson JL, Byrd JC, Lozanski G, Blum KA, Powell BL, et al. Improved efficacy using rituximab and brief duration, high intensity chemotherapy with filgrastim support for Burkitt or aggressive lymphomas: cancer and Leukemia Group B study 10 002. Br J Haematol. (2014) 165:10211. doi: $10.1111 /$ bjh.12736

21. Thomas DA, Cortes J, O'Brien S, Pierce S, Faderl S, Albitar M, et al. HyperCVAD program in Burkitt's-type adult acute lymphoblastic leukemia. J Clin Oncol. (1999) 17:2461-70. doi: 10.1200/JCO.1999.17.8.2461

22. Thomas DA, Faderl S, O’Brien S, Bueso-Ramos C, Cortes J, Garcia-Manero $\mathrm{G}$, et al. Chemoimmunotherapy with hyper-CVAD plus rituximab for the treatment of adult Burkitt and Burkitt-type lymphoma or acute lymphoblastic leukemia. Cancer. (2006) 106:1569-80. doi: 10.1002/cncr.21776

23. Jacobson C, LaCasce A. How I treat Burkitt lymphoma in adults. Blood. (2014) 124:2913-20. doi: 10.1182/blood-2014-06-538504

24. Gopal S, Gross TG. How I treat Burkitt lymphoma in children, adolescents, and young adults in sub-Saharan Africa. Blood. (2018) 132:254-63. doi: 10.1182/blood-2018-04-844472

25. Oyama T, Ichimura K, Suzuki R, Suzumiya J, Ohshima K, Yatabe $\mathrm{Y}$, et al. Senile EBV+ B-cell lymphoproliferative disorders: a clinicopathologic study of 22 patients. Am J Surg Pathol. (2003) 27:16-26. doi: 10.1097/00000478-200301000-00003

26. Hakim FT, Gress RE. Immunosenescence: deficits in adaptive immunity in the elderly. Tissue Antigens. (2007) 70:179-89. doi: 10.1111/j.1399-0039.2007.00891.x

27. Hong JY, Yoon DH, Suh C, Huh J, Do IG, Sohn I, et al. EBV-positive diffuse large B-cell lymphoma in young adults: is this a distinct disease entity? Ann Oncol. (2015) 26:548-55. doi: 10.1093/annonc/mdu556

28. Nicolae A, Pittaluga S, Abdullah S, Steinberg SM, Pham TA, Davies-Hill $\mathrm{T}$, et al. EBV-positive large B-cell lymphomas in young patients: a nodal lymphoma with evidence for a tolerogenic immune environment. Blood. (2015) 126:863-72. doi: 10.1182/blood-2015-02-630632

29. Swerdlow SH, Campo E, Pileri SA, Harris NL, Stein H, Siebert R, et al. The 2016 revision of the World Health Organization classification of lymphoid neoplasms. Blood. (2016) 127:2375-90. doi: 10.1182/blood-2016-01643569

30. Oyama T, Yamamoto K, Asano N, Oshiro A, Suzuki R, Kagami Y, et al. Age-related EBV-associated B-cell lymphoproliferative disorders constitute a distinct clinicopathologic group: a study of 96 patients. Clin Cancer Res. (2007) 13:5124-32. doi: 10.1158/1078-0432.CCR-06-2823

31. Trappe RU, Dierickx D, Zimmermann H, Morschhauser F, Mollee P, Zaucha $\mathrm{JM}$, et al. Response to rituximab induction is a predictive marker in B-cell post-transplant lymphoproliferative disorder and allows successful stratification into rituximab or R-CHOP consolidation in an international, prospective, multicenter phase II trial. J Clin Oncol. (2017) 35:536-43. doi: 10.1200/JCO.2016.69.3564

32. Ok CY, Li L, Xu-Monette ZY, Visco C, Tzankov A, Manyam GC, et al. Prevalence and clinical implications of epstein-barr virus infection in de novo diffuse large B-cell lymphoma in Western countries. Clin Cancer Res. (2014) 20:2338-49. doi: 10.1158/1078-0432.CCR-13-3157

33. Park S, Lee J, Ko YH, Han A, Jun HJ, Lee SC, et al. The impact of EpsteinBarr virus status on clinical outcome in diffuse large B-cell lymphoma. Blood. (2007) 110:972-8. doi: 10.1182/blood-2007-01-067769

34. LaCasce AS. Post-transplant lymphoproliferative disorders. Oncologist. (2006) 11:674-80. doi: 10.1634/theoncologist.11-6-674 
35. Weissmann DJ, Ferry JA, Harris NL, Louis DN, Delmonico F, Spiro I. Posttransplantation lymphoproliferative disorders in solid organ recipients are predominantly aggressive tumors of host origin. Am J Clin Pathol. (1995) 103:748-55. doi: 10.1093/ajcp/103.6.748

36. Jacobson CA, LaCasce AS. Lymphoma: risk and response after solid organ transplant. Oncology. (2010) 24:936-44.

37. Engels EA, Pfeiffer RM, Fraumeni JF Jr, Kasiske BL, Israni AK, Snyder JJ, et al. Spectrum of cancer risk among US solid organ transplant recipients. JAMA. (2011) 306:1891-901. doi: 10.1001/jama.2011.1592

38. Dierickx D, Habermann TM. Post-transplantation lymphoproliferative disorders in adults. $N$ Engl J Med. (2018) 378:549-62. doi: 10.1056/NEJMra1702693

39. Swerdlow SH, Campo E, Harris NL, Jaffe ES, Pileri SA, Stein H, et al, editors. Post-transplant lymphoproliferative disorders In: WHO Classification of Tumors of Haematopoietic and Lymphoid Tissues, 4th ed. Lyon: IARC Press (2017). p. 453-62.

40. Luskin MR, Heil DS, Tan KS, Choi S, Stadtmauer EA, Schuster SJ, et al. The impact of EBV status on characteristics and outcomes of posttransplantation lymphoproliferative disorder. Am J Transplant. (2015) 15:2665-73. doi: 10.1111/ajt.13324

41. Morscio J, Dierickx D, Ferreiro JF, Herreman A, Van Loo P, Bittoun E, et al. Gene expression profiling reveals clear differences between EBV-positive and EBV-negative posttransplant lymphoproliferative disorders. Am J Transplant. (2013) 13:1305-16. doi: 10.1111/ajt.12196

42. Dierickx D, Tousseyn T, Sagaert X, Fieuws S, Wlodarska I, Morscio J, et al. Single-center analysis of biopsy-confirmed posttransplant lymphoproliferative disorder: incidence, clinicopathological characteristics and prognostic factors. Leuk Lymphoma. (2013) 54:2433-40. doi: 10.3109/10428194.2013.780655

43. Kampers J, Orjuela-Grimm M, Schober T, Schulz TF, Stiefel M, Klein C, et al. Classical Hodgkin lymphoma-type PTLD after solid organ transplantation in children: a report on 17 patients treated according to subsequent GPOH-HD treatment schedules. Leuk Lymphoma. (2017) 58:6338. doi: 10.1080/10428194.2016.1205742

44. Opelz G, Dohler B. Lymphomas after solid organ transplantation: a collaborative transplant study report. Am J Transplant. (2004) 4:222-30. doi: 10.1046/j.1600-6143.2003.00325.x

45. Dierickx D, Tousseyn T, Gheysens O. How I treat posttransplant lymphoproliferative disorders. Blood. (2015) 126:2274-83. doi: 10.1182/blood-2015-05-615872

46. Landgren O, Gilbert ES, Rizzo JD, Socié G, Banks PM, Sobocinski KA, et al. Risk factors for lymphoproliferative disorders after allogeneic hematopoietic cell transplantation. Blood. (2009) 113:4992-5001. doi: 10.1182/blood-2008-09-178046

47. Uhlin M, Wikell H, Sundin M, Blennow O, Maeurer M, Ringden O, et al. Risk factors for Epstein-Barr virus-related post-transplant lymphoproliferative disease after allogeneic hematopoietic stem cell transplantation. Haematologica. (2014) 99:346-52. doi: 10.3324/haematol.2013.087338

48. Kanakry JA, Kasamon YL, Bolanos-Meade J, Borrello IM, Brodsky RA, Fuchs EJ, et al. Absence of post-transplantation lymphoproliferative disorder after allogeneic blood or marrow transplantation using post-transplantation cyclophosphamide as graft-versus-host disease prophylaxis. Biol Blood Marrow Transplant. (2013) 19:1514-17. doi: 10.1016/j.bbmt.2013.07.013

49. Al-Mansour Z, Nelson BP, Evens AM. Post-transplant lymphoproliferative disease (PTLD): risk factors, diagnosis, and current treatment strategies. Curr Hematol Malig Rep. (2013) 8:173-83. doi: 10.1007/s11899-013-0162-5

50. Caillard S, Dharnidharka V, Agodoa L, Bohen E, Abbott K. Posttransplant lymphoproliferative disorders after renal transplantation in the United States in era of modern immunosuppression. Transplantation. (2005) 80:1233-43. doi: 10.1097/01.tp.0000179639.98338.39

51. Sampaio MS, Cho YW, Shah T, Bunnapradist S, Hutchinson IV. Impact of Epstein-Barr virus donor and recipient serostatus on the incidence of post-transplant lymphoproliferative disorder in kidney transplant recipients. Nephrol Dial Transplant. (2012) 27:2971-9. doi: 10.1093/ndt/gfr769

52. Walker RC, Marshall WF, Strickler JG, Wiesner RH, Velosa JA, Habermann TM, et al. Pretransplantation assessment of the risk of lymphoproliferative disorder. Clin Infect Dis. (1995) 20:1346-53. doi: 10.1093/clinids/20. 5.1346
53. Evens AM, David KA, Helenowski I, Nelson B, Kaufman D, Kircher SM, et al. Multicenter analysis of 80 solid organ transplantation recipients with post-transplantation lymphoproliferative disease: outcomes and prognostic factors in the modern era. J Clin Oncol. (2010) 28:1038-46. doi: 10.1200/JCO.2009.25.4961

54. Ghobrial IM, Habermann TM, Maurer MJ, Geyer SM, Ristow KM, Larson TS, et al. Prognostic analysis for survival in adult solid organ transplant recipients with post-transplantation lymphoproliferative disorders. J Clin Oncol. (2005) 23:7574-82. doi: 10.1200/JCO.2005.01.0934

55. Caillard S, Porcher R, Provot F, Dantal J, Choquet S, Durrbach A, et al. Post-transplantation lymphoproliferative disorder after kidney transplantation: report of a nationwide French registry and the development of a new prognostic score. J Clin Oncol. (2013) 31:1302-9. doi: 10.1200/JCO.2012.43.2344

56. Dierickx D, Tousseyn T, Morscio J, Fieuws S, Verhoef G. Validation of prognostic scores in post-transplantation lymphoproliferative disorders. $J$ Clin Oncol. (2013) 31:3443-4. doi: 10.1200/JCO.2013.50.3326

57. Reshef R, Vardhanabhuti S, Luskin MR, Heitjan DF, Hadjiliadis D, Goral S, et al. Reduction of immunosuppression as initial therapy for posttransplantation lymphoproliferative disorder (bigstar). Am J Transplant. (2011) 11:336-47. doi: 10.1111/j.1600-6143.2010.03387.x

58. Parker A, Bowles K, Bradley JA, Emery V, Featherstone C, Gupte G, et al. Management of post-transplant lymphoproliferative disorder in adult solid organ transplant recipients - BCSH and BTS Guidelines. Br J Haematol. (2010) 149:693-705. doi: 10.1111/j.1365-2141.2010.08160.x

59. Styczynski J, van der Velden W, Fox CP, Engelhard D, de la Camara $\mathrm{R}$, Cordonnier C, et al. Management of Epstein-Barr virus infections and post-transplant lymphoproliferative disorders in patients after allogeneic hematopoietic stem cell transplantation: Sixth European Conference on Infections in Leukemia (ECIL-6) guidelines. Haematologica. (2016) 101:80311. doi: 10.3324/haematol.2016.144428

60. Trappe R, Oertel S, Leblond V, Mollee P, Sender M, Reinke P, et al. Sequential treatment with rituximab followed by CHOP chemotherapy in adult Bcell post-transplant lymphoproliferative disorder (PTLD): the prospective international multicentre phase 2 PTLD-1 trial. Lancet Oncol. (2012) 13:196206. doi: 10.1016/S1470-2045(11)70300-X

61. Heslop HE, Slobod KS, Pule MA, Hale GA, Rousseau A, Smith CA, et al. Long-term outcome of EBV-specific T-cell infusions to prevent or treat EBVrelated lymphoproliferative disease in transplant recipients. Blood. (2010) 115:925-35. doi: 10.1182/blood-2009-08-239186

62. Savoldo B, Goss JA, Hammer MM, Zhang L, Lopez T, Gee AP, et al. Treatment of solid organ transplant recipients with autologous Epstein Barr virus-specific cytotoxic T lymphocytes (CTLs). Blood. (2006) 108:2942-9. doi: 10.1182/blood-2006-05-021782

63. Haque T, Wilkie GM, Jones MM, Higgins CD, Urquhart G, Wingate P, et al. Allogeneic cytotoxic T-cell therapy for EBV-positive posttransplantation lymphoproliferative disease: results of a phase 2 multicenter clinical trial. Blood. (2007) 110:1123-31. doi: 10.1182/blood-2006-12-063008

64. Bollard CM, Gottschalk S, Torrano V, Diouf O, Ku S, Hazrat Y, et al. Sustained complete responses in patients with lymphoma receiving autologous cytotoxic T lymphocytes targeting Epstein-Barr virus latent membrane proteins. J Clin Oncol. (2014) 32:798-808. doi: 10.1200/JCO.2013.51.5304

65. Ouyang J, Juszczynski P, Rodig SJ, Green MR, O’Donnell E, Currie T, et al. Viral induction and targeted inhibition of galectin-1 in EBV+ posttransplant lymphoproliferative disorders. Blood. (2011) 117:4315-22. doi: 10.1182/blood-2010-11-320481

66. Green MR, Rodig S, Juszczynski P, Ouyang J, Sinha P, O’Donnell E, et al. Constitutive AP-1 activity and EBV infection induce PD-L1 in Hodgkin lymphomas and posttransplant lymphoproliferative disorders: implications for targeted therapy. Clin Cancer Res. (2012) 18:1611-8. doi: 10.1158/1078-0432.CCR-11-1942

67. Armand P. Immune checkpoint blockade in hematologic malignancies. Blood. (2015) 125:3393-400. doi: 10.1182/blood-2015-02-567453

68. Kinch A, Sundstrom C, Baecklund E, Backlin C, Molin D, Enblad G. Expression of PD-1, PD-L1, and PD-L2 in posttransplant lymphoproliferative disorder after solid organ transplantation. Leuk Lymphoma. (2018). doi: 10.1080/10428194.2018.1480767. [Epub ahead of print]. 
69. AlDabbagh MA, Gitman MR, Kumar D, Humar A, Rotstein C, Husain S. The role of antiviral prophylaxis for the prevention of Epstein-Barr virus-associated posttransplant lymphoproliferative disease in solid organ transplant recipients: a systematic review. Am J Transplant. (2017) 17:770-81. doi: 10.1111/ajt.14020

70. Ghosh SK, Perrine SP, Faller DV. Advances in virus-directed therapeutics against Epstein-Barr virus-associated malignancies. Adv Virol. (2012) 2012:509296. doi: 10.1155/2012/509296

71. Snijder J, Ortego MS, Weidle C, Stuart AB, Gray MD, McElrath MJ, et al. An antibody targeting the fusion machinery neutralizes dual-tropic infection and defines a site of vulnerability on Epstein-Barr virus. Immunity. (2018) 48:799-811 e799. doi: 10.1016/j.immuni.2018.03.026

72. van Esser JW, Niesters HG, van der Holt B, Meijer E, Osterhaus AD, Gratama JW, et al. Prevention of Epstein-Barr virus-lymphoproliferative disease by molecular monitoring and preemptive rituximab in high-risk patients after allogeneic stem cell transplantation. Blood. (2002) 99:4364-9. doi: 10.1182/blood.V99.12.4364

73. van der Velden WJ, Mori T, Stevens WB, de Haan AF, Stelma FF, Blijlevens NM, et al. Reduced PTLD-related mortality in patients experiencing EBV infection following allo-SCT after the introduction of a protocol incorporating pre-emptive rituximab. Bone Marrow Transplant. (2013) 48:1465-71. doi: 10.1038/bmt.2013.84

74. San-Juan R, Manuel O, Hirsch HH, Fernández-Ruiz M, López-Medrano F, Comoli P, et al. Current preventive strategies and management of Epstein-Barr virus-related post-transplant lymphoproliferative disease in solid organ transplantation in Europe. Results of the ESGICH Questionnairebased Cross-sectional Survey. Clin Microbiol Infect. (2015) 21:604 e1-9. doi: 10.1016/j.cmi.2015.02.002

75. Ichikawa A, Arakawa F, Kiyasu J, Sato K, Miyoshi H, Niino D, et al. Methotrexate/iatrogenic lymphoproliferative disorders in rheumatoid arthritis: histology, Epstein-Barr virus, and clonality are important predictors of disease progression and regression. Eur J Haematol. (2013) 91:20-8. doi: 10.1111/ejh.12116

76. Klein A, Reinhard H, Mueller AM, Horneff G. Spontaneous regression of Epstein-Barr virus-associated lymphoproliferative disorder in a juvenile idiopathic arthritis patient after the discontinuation of methotrexate and etanercept. Eur J Rheumatol. (2017) 4:136-8. doi: 10.5152/eurjrheum.2016.032

77. Abruzzo LV, Rosales CM, Medeiros LJ, Vega F, Luthra R, Manning JT, et al. Epstein-Barr virus-positive B-cell lymphoproliferative disorders arising in immunodeficient patients previously treated with fludarabine for low-grade B-cell neoplasms. Am J Surg Pathol. (2002) 26:630-6. doi: 10.1097/00000478-200205000-00009

78. Adams B, Lazarchick J, Medina AM, Willner IR, Neville B, Murphy E, et al. Iatrogenic immunodeficiency-associated lymphoproliferative disease of the Hodgkin lymphoma-like variant in a patient treated with mycophenolate mofetil for autoimmune hepatitis. Am J Hematol. (2010) 85:627-9. doi: 10.1002/ajh.21753

79. Natkunam Y, Gratzinger D, Chadburn A, Goodlad JR, Chan JKC, Said J, et al. Immunodeficiency-associated lymphoproliferative disorders: time for reappraisal? Blood. (2018) 32:1871-8. doi: 10.1182/blood-2018-04-842559

Conflict of Interest Statement: The authors declare that the research was conducted in the absence of any commercial or financial relationships that could be construed as a potential conflict of interest.

Copyright (C) 2019 Crombie and LaCasce. This is an open-access article distributed under the terms of the Creative Commons Attribution License (CC BY). The use, distribution or reproduction in other forums is permitted, provided the original author(s) and the copyright owner(s) are credited and that the original publication in this journal is cited, in accordance with accepted academic practice. No use, distribution or reproduction is permitted which does not comply with these terms. 